\title{
Adjustment and Happiness of Post Graduate Students In Relation To Loneliness
}

\author{
Mr. Appasaheb C. Patil ${ }^{1}$, Ms. Usha R. Gouda ${ }^{2}$, Dr. Shanmukh V. Kamble ${ }^{3}$
}

\section{ABSTRACT}

The study was conducted with the main objective to study the significance of relationship of adjustment and happiness of male and female students with loneliness. To find out the gender difference on adjustment, happiness and loneliness. A random sample 100 male and 100 female students studying in various department of University were selected for the study. They were administered with UCLA loneliness scale (Russell D. 1996), CAT (Pennebaker, J.W., Colder, M., and Sharp, L.K. 1990) and Subjective happiness scale (Lyubomirsky, S., and Lepper, H, 1999). The results revealed that the female students with high negative affect have expressed significantly higher loneliness. The male students with high loneliness have expressed lower positive affect, higher negative affect, home sickness and higher overall adjustment problems. This study calls for a planned intervention program for the students who are new; come to join University and further calls from imparting coping skills.

Keywords: Adjustment, Happiness, Loneliness

Beginning college is often the first major transition that adolescents undergo (Gall, Evans, Bellerose, 2000) and this experience can significantly impact students' mental health (e.g., Frazier \& Schauben, 1994). Compared to same aged peers who are not attending college, students are more likely to experience maladjustment in the form of acute loneliness and isolation (Berman \& Sperling, 1991), and depression (Radloff, 1991).

Loneliness can be defined as "distressful consciousness of an inner distance to other humans and thus as a desire for satisfying and meaningful relations” (Schwab, 1997). According to this definition, it is important to differentiate between loneliness and the status of being alone (Peplau and Perlman, 1982 and Perlman and Peplau, 1981). Thus, loneliness is a more

\footnotetext{
${ }^{1}$ Research Scholar, Department of Psychology, Karnatak University Dharwad, Karnataka, India

${ }^{2}$ Post Graduate Student, Department of Psychology, Karnatak University Dharwad Karnataka, India

${ }^{3}$ Associate Professor, Department of Psychology, Karnatak University Dharwad, Karnataka, India

*Responding Author

(C) 2016, A Patil, U Gouda, S Kamle; licensee IJIP. This is an Open Access Research distributed under the terms of the Creative Commons Attribution License (http://creativecommons.org/licenses/by/2.0), which permits unrestricted use, distribution, and reproduction in any Medium, provided the original work is properly cited.
} 


\section{Adjustment and Happiness of Post Graduate Students In Relation To Loneliness}

subjective, emotional, and cognitive appraisal of a person's position in his/her social environment rather than the pure absence of social support or social networks (Macdonald, Hayes, \& Baglioni, 2000).

“Adjustment” can be defined as a process of altering one's behavior to reach a harmonious relationship with their environment. This is typically a response brought about by some type of change that has taken place. The stress of this change causes one to try to reach a new type of balance or homeostasis between the individual (both inwardly and outwardly), and with their environment.

According to Coleman, James $\boldsymbol{C}$., "Adjustment is the outcome of the individual's attempts to deal with the stress and meet his needs: also his efforts to maintain harmonious relationships with the environment.

Through the past century, psychologists have mainly focused on human unhappiness (such as anxiety and depression) and neglected the positive aspect of human potential. Only until comparatively recently, especially after Bradburn's (1969) discovery of the independence of positive and negative affect, that psychologists have started to look at the correlates, definitions and predictors of happiness (Argyle, 1987; Eysenck, 1990; Myers, 1992; Seligman and Csikszentmihalyi, 2000). Argyle et al. (1989) defined happiness as having three partly independent components: (1) the average level of satisfaction over a specific time period; (2) the frequency and degree of positive affect; and (3) the relative absence of negative affect.

Sonja Lyubomirsky, “The How of Happiness” a professor of psychology at the University of California, defines happiness as, "the experience of joy, contentment, or positive well-being, combined with a sense that one's life is good, meaningful, and worthwhile.”

College life is full of new experiences, and lots of anxieties (Sax, 1997). In addition to surviving academically and preparing themselves for a career, students are becoming independent adults, creating personal value systems, and developing significant social relationships. Separated from their parents and family, perhaps for the first time, students may feel alone and lonely in a new community often with minimal social support. From selecting classes to navigating social waters, these pressures can overwhelm the student. These new experiences challenge their newfound independence, sense of self, ethical standards, and may lead to a host of mental health problems, including loneliness. Loneliness is caused not by being alone but by being without some definite needed relationship or set of relationships. Many students have reported experiencing loneliness (Wiseman, Guttfeund \& Lurie, 1995), and loneliness among students has been associated with rates of dropping out of school, suicide and suicide ideation, and alcoholism (Cutrona, 1982; Medora \& Woodward, 1986; Cacioppo, Hughes, Waite, Hawkley, \&Thisted, 2006). Lonely students are more apt to become depressed, suicidal, and engage in self-destructive behaviors 


\section{Adjustment and Happiness of Post Graduate Students In Relation To Loneliness}

(Hermann \& Betz, 2006). Lonely and socially isolated individuals are more likely to have low self-esteem (Friedlander et al., 2007), and lacking adequate social skills to socialize easily with others can severely isolate an individual, exacerbating their loneliness. In situation student who are suffering from loneliness try to alleviate their loneliness by using adjustment strategies, happiness strategy so they will have better adjustment.

\section{LITERATURE REVIEW}

Enrico Di Tommaso, Barry Spinner (1973) presented the development and initial validation of the Social and Emotional Loneliness Scale for Adults (SELSA), a multidimensional measure of loneliness. The results from principal components analyses support Weiss' (1973; the experience of emotional and social isolation Cambridge: MIT Press) conception that social and emotional loneliness are distinct states. They also indicate that emotional loneliness can be broken into two types: romantic and family emotional loneliness. All subscales have high internal consistencies, with Cronbach alphas ranging from 0.89 to 0.93. Examination of the SELSA's relationship to several other criteria, including the revised UCLA Loneliness Scale, the Dyadic Adjustment Scale, and dating frequency, indicate it has good concurrent, discriminant and convergent validity.

Enrico DiTommaso, Cyndi Brannen-McNulty, Lynda Ross, Melissa Burgess (2003) studied a total of 183 university students who completed measures of attachment, social and emotional loneliness, and social skills. It indicated that secure attachment and social skills are related on several significant dimensions. Other findings reveal that attachment security and social skills are significantly related to loneliness. These results lend support to the notion that securely attached individuals are socially skilled, and that social competence is related to lower perceived levels of loneliness. Finally, regression analyses indicated that the link between secure and fearful attachment, and social loneliness was mediated, in part, by social skills. It is suggested that attachment theory may provide a useful framework for the study of social competence and adjustment.

Clare M. Stocker (1994) links between children's psychological adjustment and individual differences in their perceptions of relationships with siblings, mothers, and friends were studied in a sample of 85 second-graders. It indicated that characteristics of these relationships were significantly correlated with children's loneliness, depressive mood, self-esteem, and behavioral conduct. Children who reported that their relationships with mothers, friends, or mothers and friends were characterized by high levels of warmth had significantly better adjustment outcomes than children who reported low levels of warmth in relationships with both friends and mothers. The importance of the network of children's relationships for their mental health is discussed.

Mauss, Iris B.; Savino, Nicole S.; Anderson, Craig L.; Weisbuch, Max; Tamir, Maya; Laudenslager, Mark L. (2012) in their study, they suggested that the more people value 


\section{Adjustment and Happiness of Post Graduate Students In Relation To Loneliness}

happiness, the lonelier they feel on a daily basis provides an experimental manipulation of valuing happiness and demonstrates that inducing people to value happiness leads to relatively greater loneliness, as measured by self reports and a hormonal index (progesterone). These findings suggest that wanting to be happy can make people lonely.

Booth, Richard; Bartlett, David; Bohnsack, Joel (1992) studied 55 undergraduates who completed the Revised UCLA Loneliness Scale, the Social Reticence Scale, and the Psychap Inventory in a study that examined the relationship between happiness, loneliness, and shyness in college students. As expected, inverse relationships were found between happiness and shyness and between happiness and loneliness, and a positive relationship was found between loneliness and shyness.

Helen Cheng and Adrian Furnham (2002) examined to what extent peer relations, self confidence, and school performance correlated with self-rated happiness (OHI) and loneliness (UCLA LS) in adolescents. Personality traits (EPQ), self-confidence (PEI), friendship and school grades were all significantly oppositely correlated with happiness and loneliness. Regressional analysis revealed that extraversion and neuroticism were direct predictors of happiness and selfconfidence, while psychoticism and extraversion were direct predictors of loneliness. The effect of sex on happiness and loneliness was moderated by friendship and neuroticism, and by neuroticism and psychoticism, respectively. Extraversion was also a significant predictor of general confidence and social interactions which directly influenced loneliness whilst psychoticism was a direct predictor of loneliness. Self-rated school performance was the only direct predictor of happiness whereas general confidence and social interactions were related to adolescents' self-reported loneliness.

\section{Objectives of the Study}

1.To find out the significance of the relationship of adjustment, happiness of male and female students with their loneliness.

2.To find out the significant gender difference on adjustment, happiness and loneliness.

\section{Hypotheses}

1. Ha ${ }_{1}$ Adjustment and happiness of male and female students is significantly and positively related to their loneliness.

Ha $_{1.1}$ Positive affect, negative affect, home sickness, overall adjustment is significantly and positively related to loneliness of male students.

$\mathbf{H a}_{1.2}$ Happiness is significantly and positively related to loneliness of male students.

$\mathbf{H a}_{1.3}$ Positive affect, negative affect, home sickness, overall adjustment of female students significantly and positively related to loneliness.

$\mathbf{H a}_{1.4}$ Happiness is significantly and positively related to loneliness of female students. 


\section{Adjustment and Happiness of Post Graduate Students In Relation To Loneliness}

2. Ha $\mathrm{H}_{2}$ There is significant difference between the male and female students on adjustment and happiness and loneliness.

$\mathbf{H a}_{2.1}$ There is a significant difference between the male and female students on positive affect, negative affect, home sickness, overall adjustment.

$\mathbf{H a}_{2.2}$ There is a significant difference between the male and female students on happiness. $\mathbf{H a}_{2.3}$ There is a significant difference between male and female students as loneliness.

\section{METHOD}

\section{Sample}

A random sample of 100 males and 100 females students studying in various departments of Karnatak University were selected for the study.

Table Showing the Difference of Sample in terms of Sex, $N$ and Mean Age

Tools

\begin{tabular}{|c|c|c|c|}
\hline SL NO & SEX & N & Mean Age \\
\hline 1 & Male & 100 & 22 \\
\hline 2 & Female & 100 & 24 \\
\hline & Total & 200 & \\
\hline
\end{tabular}

\section{Personal Data Sheet}

A personal data sheet was prepared by the researcher to obtain demographic details such as age, gender, domicile, education status etc of the subjects.

\section{UCLA Loneliness Scale.}

It was developed by Russell, D. (1996). A 20-item scale designed to measure one’s subjective feelings of loneliness as well as feelings of social isolation. Participants rate each item on ascale from 1 (Never) to 4 (Often). This measure is a revised version of both the original UCLA Loneliness Scale and the Revised UCLA Loneliness Scale. The first revision was done to make 10 of the 20 original items reverse scored. The second revision was done to simplify the scale so less educated population could comprehend it. Internal consistency reported coefficient alpha of .96 , test retest over 2 month $(\alpha .73)$.

\section{College Adjustment Scale (CAT).}

It was developed by Pennebaker, J.W., Colder, M., and Sharp, L.K. (1990).This 19-term survey taps the degree to which students have experienced a variety of thoughts and feelings about being in college. There are four dimension Positive affect (there are 6 items), Negative affect (there are 9 items), Home sickness (there are 5 items) and Overall adjustments. Cronbach alpha .79; 2 month of test-retest.65. Three stable factors have emerged that general negative affect, positive affect, home sickness and overall adjustment.

\section{Subjective Happiness Scale.}

It was developed by Lyubomirsky, S., \&Lepper, H. (1999). To score the scale, reverse code the 4th item (i.e., turn a 7 into a 1, a 6 into a 2, a 5 into a 3, a 3 into a 5, a 2 into a 6, and a 1 into a 7), and compute the mean of the 4 items.. Results have indicated that the SHS has high internal consistency, which has been found to be stable across samples. Test-retest and self-peer 


\section{Adjustment and Happiness of Post Graduate Students In Relation To Loneliness}

correlations have suggested good to excellent reliability, and construct validation studies of convergent and discriminant validity have confirmed the use of this scale to measure he construct of subjective happiness.

\section{Variables}

1. Dependent variable: Adjustment and Happiness.

2. Independent variable: Loneliness.

\section{Operational Definition}

Loneliness: Loneliness is the exceedingly unpleasant and driving experience connected with inadequate discharge of the need for human intimacy, for interpersonal intimacy.

Adjustment: “Adjustment is the process by which living organism maintain a balance between his needs and the circumstances that influence the satisfaction of these needs".

Happiness: "The experience of joy, contentment, or positive well-being, combined with a sense that one's life is good, meaningful and worthwhile”.

\section{Statistical Techniques:}

The following statistical techniques are applied to analyze the score obtained and to verify the main hypothesis as well as their specific forms.

1. 't' test.

It was applied to study the gender difference on Loneliness, Adjustment and Happiness of the male and female students.

\section{Karl Pearson's correlation coefficient.}

It was applied to verify the hypothesis $\mathrm{Ha}_{2}$ to check the significant of relation of adjustment, happiness with loneliness in male and female students the correlation coefficient technique is applied.

\section{RESULTS AND DISCUSSION}

The whole plan of analyzing the data started with calculation of mean and standard deviation for the scores of loneliness, college adjustment and happiness of both male and female students.

Table-1: Showing the N, Mean, Standard Deviation for loneliness and college adjustment and Happiness of male students $(N=100)$

Male

\begin{tabular}{|c|c|c|c|c|}
\hline Sl. No & Variables & Dimensions & Mean & SD \\
\hline 1 & Loneliness & & 49.74 & 9.70 \\
\hline \multirow{3}{*}{2} & \multirow{3}{*}{ CAT } & Positive affect & 50.02 & 10.71 \\
\cline { 3 - 5 } & & Negative affect & 48.35 & 8.93 \\
\cline { 3 - 5 } & & Home sickness & 49.11 & 9.84 \\
\cline { 3 - 5 } & & Overall adjustment & 47.71 & 9.25 \\
\hline 3 & Happiness & & 49.04 & 2.45 \\
\hline
\end{tabular}

(C) The International Journal of Indian Psychology, ISSN 2348-5396 (e)| ISSN: 2349-3429 (p) | 63 


\section{Adjustment and Happiness of Post Graduate Students In Relation To Loneliness}

An observation of the table mean score reveals that loneliness of the male students is 49.74 indicating that it is below average.

As for as the college adjustment is concerned, on some dimensions it is just average namely positive affect (50.02) as for as the other dimensions of negative affect (48.35), home sickness (49.11), overall adjustment (47.71) indicating that it is below average.

On the Happiness (49.04) it is below average. Finally one can understand that all the variables namely loneliness. College adjustment (dimension wise) and happiness are well pronounced in male students.

Table-2: Showing the Loneliness, Adjustment and Happiness in terms of Mean, Standard Deviation in female students. $(N=100)$

Female

\begin{tabular}{|c|c|c|c|c|}
\hline Sl. No & Variables & Dimensions & Mean & SD \\
\hline 1 & Loneliness & & 50.26 & 10.32 \\
\hline \multirow{3}{*}{2} & \multirow{3}{*}{ CAT } & Positive affect & 49.98 & 9.28 \\
\cline { 3 - 5 } & & Negative affect & 51.65 & 10.75 \\
\cline { 3 - 5 } & & Home sickness & 50.89 & 10.12 \\
\cline { 3 - 5 } & & Overall adjustment & 52.29 & 10.23 \\
\hline 3 & Happiness & & 50.96 & 13.89 \\
\hline
\end{tabular}

An observation of the table mean score reveals that loneliness of the female students is (50.26) indicating it is just average.

On college adjustment is concerned on some dimension are indicating above average namely negative affect (51.65) and overall adjustment (52.29) on dimension of home sickness (50.89) it is indicating just average, on the dimension of positive affect (49.98) indicating that below average. On Happiness (50.96) indicating just average.

Finally Loneliness, college adjustment and happiness are well pronounced in female students.

Table-3: Showing the Mean, Standard Deviation and ' $t$ ' value for loneliness, college adjustment of male and female students. ( $N=200, M=100, f=100)$.

\begin{tabular}{|c|c|c|c|c|c|}
\hline \multirow{2}{*}{ VARIABLE } & \multicolumn{2}{|c|}{ MALE } & \multicolumn{2}{c|}{ FEMALE } & \multirow{2}{*}{ 't' VALUE } \\
\cline { 2 - 5 } & Mean & $\begin{array}{c}\text { Standard } \\
\text { Deviation }\end{array}$ & Mean & $\begin{array}{c}\text { Standard } \\
\text { Deviation }\end{array}$ & \\
\hline Loneliness & 49.74 & 9.70 & 50.26 & 10.32 & .37 \\
\hline Positive affect & 50.02 & 10.71 & 49.98 & 9.28 & .035 \\
\hline Negative affect & 48.35 & 8.93 & 51.65 & 10.75 & $2.36^{*}$ \\
\hline Home sickness & 49.11 & 9.84 & 50.89 & 10.12 & 1.26 \\
\hline Overall adjustment & 47.71 & 9.25 & 52.29 & 10.23 & $3.31^{*}$ \\
\hline Happiness & 49.04 & 2.45 & 50.96 & 13.89 & 1.35 \\
\hline
\end{tabular}

* $\mathbf{p}<0.05$; significant

(C) The International Journal of Indian Psychology, ISSN 2348-5396 (e)| ISSN: 2349-3429 (p) | 64 


\section{Adjustment and Happiness of Post Graduate Students In Relation To Loneliness}

On observation of table reveals that the difference between male and female students is not significant $(\mathrm{t}=.37 \mathrm{p}>0.05)$ in their loneliness. It means that the male and female students have experienced same level of loneliness in terms of lack of companionship, feeling alone, lack of friends, isolated from others, shy, could not talk to people, no longer close to any one friends.

On the adjustment dimension namely positive affect there is no significant difference between the male and female students $(\mathrm{t}=.03 \mathrm{p}>0.05)$ it reveals that male and female students have experienced the same level of positive affect in terms of thinking about classmates, roommates, about their social life, college, about their optimistic thinking and about their future.

On the negative effect there is significant difference between male and female students ( $t=-$ $2.3 p<0.05$ ) interpretation goes as female students have expressed negative affect in other words; the female students have experienced worry, angry, lonely, nervous and depressed when compared to the male students.

When compared to the male students on the dimension of home sickness there is no significant difference between male and female students $(-1.2 p>0.05)$ it means that the male and female students expressed the same level of home sickness in terms of thinking about home, family members, parents, worried about academic performance, intimate relationship with others.

On the dimension of overall adjustment there is a significant difference between male and female students $(-3.3 p<0.05)$ the interpretation goes as the female students are have maladjustment problems. In overall adjustment it means that female students expressed less positive affect, home sickness and all adjustment more negative affect when compared with the male students. On the dimension of happiness there is no significant difference between male and female students $(1.3 \mathrm{p}>0.05)$ in their happiness it means that male and female students have expressed same level of happiness experienced.

The technique of correlation coefficient analysis is to verify the hypothesis $\mathrm{Ha}_{2}$ the obtained correlated coefficient revealed the relationship of Loneliness, College adjustment, Happiness in terms of direction and magnitude.

Table-4: Showing correlation coefficient for Loneliness of female students with College Adjustment.

\begin{tabular}{|c|c|c|c|c|}
\hline Loneliness & Positive Affect & $\begin{array}{c}\text { Negative } \\
\text { Affect }\end{array}$ & Home Sickness & $\begin{array}{c}\text { Overall } \\
\text { Adjustment }\end{array}$ \\
\hline & .193 & $.33^{*}$ & .08 & .04 \\
\hline
\end{tabular}

${ }^{*} \mathbf{p}<.05$

A look at the table shows the correlation coefficient between loneliness and adjustment. It is observed that there is significant correlation between the dimension namely negative affect

(C) The International Journal of Indian Psychology, ISSN 2348-5396 (e)| ISSN: 2349-3429 (p) | 65 


\section{Adjustment and Happiness of Post Graduate Students In Relation To Loneliness}

$(r=.33 p<0.05)$. It means that female students with higher negative affect have expressed loneliness. It can be inferred that loneliness of the female students significantly and positively related to negative affect, it means that female students who are worried about the academic performance at college, worried about love or intimate relationship with others, impression make to others, how to be college in general, are angry, lonely, anxious and depressed. They have realized that they cannot change their living condition so, they accepted their present condition.

Further observation of the college on the adjustment dimension namely positive affect $(\mathrm{r}=.19 \mathrm{p}>0.05)$, home sickness $(\mathrm{r}=.08>0.05)$ and overall adjustment $(\mathrm{r}=.04 \mathrm{p}>0.05)$ there is no significant relationship with loneliness.

Table-5: Showing the correlation coefficient for Loneliness of female students with happiness.

\begin{tabular}{|c|c|}
\hline Loneliness & Happiness \\
\hline & .11 \\
\hline
\end{tabular}

${ }^{*} \mathbf{p}<.05$

A look at the table shows correlation coefficient between loneliness and happiness $(\mathrm{r}=.11>0.05)$ is not significant.

Table-6: Showing the correlation coefficient for Loneliness of male students with college adjustment.

\begin{tabular}{|c|c|c|c|c|}
\hline Loneliness & Positive Affect & Negative Affect & Home Sickness & $\begin{array}{c}\text { Overall } \\
\text { Adjustment }\end{array}$ \\
\hline &.$-21^{*}$ & $.22^{*}$ & $.20^{*}$ & $.19^{*}$ \\
\hline
\end{tabular}

${ }^{*} \mathbf{p}<.05$

Table shows the relationship of loneliness with positive affect $\left(\mathrm{r}=.-21^{*}<0.05\right)$, negative affect $(\mathrm{r}=.22 * \mathrm{p}<0.05)$, home sickness $(\mathrm{r}=.20 *<0.05)$ and overall adjustment $(\mathrm{r}=.19 * \mathrm{p}<0.05)$ the male students with higher affect have expressed lower loneliness. Negative affect shows significantly higher loneliness, or in other words negative affect is positively and significantly related to loneliness, it can be inferred that the loneliness is experienced due to negative affect. Home sickness is positively and significantly related to Loneliness, it can be inferred that the male students with higher homesickness have expressed higher Loneliness. The male students with overall maladjustment are significantly and positively related to Loneliness. It can be inferred that male students with higher overall maladjustment have expressed significantly higher Loneliness.

The relationship of negative affect of male students with loneliness is significant $\left(\mathrm{r}=22^{*} \mathrm{p}<0.05\right)$. The male students with higher negative affect adjustment have shown significantly higher loneliness, it can be inferred that loneliness of male students significantly positively related to negative affect, The interpretation goes as male students with negative affect of have expressed loneliness in terms of worried about performance, intimate relationship, way of look, impression

(C) The International Journal of Indian Psychology, ISSN 2348-5396 (e)| ISSN: 2349-3429 (p) | 66 


\section{Adjustment and Happiness of Post Graduate Students In Relation To Loneliness}

of others, being in college with others and they feel lonely, anxious and depressed these feelings has led to loneliness.

The relationship of homesickness of male students with loneliness is significant $\left(\mathrm{r}=.20^{*}<0.05\right)$, the male students with higher home sickness have shown significantly higher loneliness. It can be inferred that loneliness of male students is positively related to home sickness; the interpretation goes as the male students have experienced in terms of missing high school friends, home, parents, other family members and they felt lonely and nervous these conditions are responsible for present condition of loneliness

The relationship of overall adjustment of the male students with loneliness is significant $(\mathrm{r}=.19 *<0.05)$. The male students with higher home sickness have shown significantly higher loneliness. It can be inferred that loneliness of male students is significantly positively related to overall adjustment. The interpretation goes as the male students are missing their high school friends, home, parents, family members, worried about academic performance, intimate relationship, way they look, being away from parents, social life, college in general, optimism about future at college and they felt angry, lonely nervous, depressed, about themselves, these conditions are responsible for feeling of loneliness.

Table-7: Showing correlation coefficient for Loneliness of male students with happiness.

\begin{tabular}{|l|l|}
\hline Loneliness & \multicolumn{1}{|c|}{ Happiness } \\
\hline &.$-25^{* *}$ \\
\hline
\end{tabular}

$* \mathbf{P}<.05$

An observation of table shows the relationship of loneliness of the male students with happiness is highly significant $\left(\mathrm{r}=.-25^{* *} \mathrm{p}<0.05\right)$

The male students with lower loneliness have shown significantly higher happiness. To cope with loneliness in other words male students have been considered about themselves, as they think of their life as enjoyment, more happiness and as lively person seem to be very happy whenever they are experiencing loneliness.

\section{CONCLUSION}

1. There is no significant difference between male and female students on loneliness.

2. The female students have expressed significant negative affect when compared with the male students.

3. The female students have expressed overall adjustment when compared with the male students.

4. There is no significant difference between male and female students on Happiness.

5. The male students with higher loneliness have shown significantly higher positive affect.

6. The male students with higher loneliness have shown significantly higher negative affect. 


\section{Adjustment and Happiness of Post Graduate Students In Relation To Loneliness}

7. The male students with higher loneliness have shown significantly higher home sickness.

8. The male students with higher loneliness have shown significantly higher overall Adjustment.

9. The male students with lower loneliness have shown higher happiness.

\section{Acknowledgments}

The author appreciates all those who participated in the study and helped to facilitate the research process.

\section{Conflict of Interests}

The author declared no conflict of interests.

\section{REFERENCES}

Arcuri, Anna, "Attachment Dimensions and Depressive Symptoms: Mediating Effects of Social Support Seeking and Loneliness among First Year Undergraduate Students" (2009). Electronic Theses and Dissertations. Paper 23.

Booth, Richard; Bartlett, David; Bohnsack, Joel (1992), An examination of the relationship between Happiness, Loneliness, and Shyness in College Students, Journal of College Student Development, Vol 33(2).

Cheng, H., \& Furnham, A. (2002). Personality, peer relations, and self-confidence as predictors of happiness and loneliness. Journal of Adolescence, 25(3), 327-339. doi:10.1006/jado.2002.0475

Cutrona, C. E. (1982). Transition to college: Loneliness and the process of social adjustment. in L. A. Peplau \& D. Perlman (Eds.), Loneliness: A sourcebook of current theory, research and therapy. New York: Wiley-Interscience.

Ditommaso, E., \& Spinner, B. (1993). The development and initial validation of the Social and Emotional Loneliness Scale for Adults (SELSA). Personality and Individual Differences, 14(1), 127-134. doi:10.1016/0191-8869(93)90182-3

Ditommaso, E., Brannen-Mcnulty, C., Ross, L., \& Burgess, M. (2003). Attachment styles, social skills and loneliness in young adults. Personality and Individual Differences, 35(2), 303312. doi:10.1016/s0191-8869(02)00190-3

John M. Ernst, John T. Cacioppo (1999), Lonely hearts: Psychological Perspective on Loneliness, Applied and Preventive Psychology, Vol. 8. Issue 1, pp. 1-22.

Lyubomirsky, S. (2008). The how of happiness: A scientific approach to getting the life you want. New York: Penguin Press.

Mauss, I. B., Savino, N. S., Anderson, C. L., Weisbuch, M., Tamir, M., \& Laudenslager, M. L. (2012). The pursuit of happiness can be lonely. Emotion, 12(5), 908-912. doi:10.1037/a0025299 


\section{Adjustment and Happiness of Post Graduate Students In Relation To Loneliness}

Stocker, C. M. (1994). Children's Perceptions of Relationships with Siblings, Friends, and Mothers: Compensatory Processes and Links with Adjustment. Journal of Child Psychology and Psychiatry, 35(8), 1447-1459. doi:10.1111/j.1469-7610.1994.tb01286.x

\section{Web References}

http://research-education-edu.blogspot.in/2012/04/adjustment.html

How to cite this article: A Patil, U Gouda, S Kamle (2016), Adjustment and Happiness of Post Graduate Students In Relation To Loneliness, International Journal of Indian Psychology, Volume 3, Issue 4, No. 67, ISSN:2348-5396 (e), ISSN:2349-3429 (p), DIP:18.01.181/20160304, ISBN:978-1-365-39397-6 